\title{
Traumatic tension pneumomediastinum mimicking cardiac tamponade
}

\author{
M H BEG, REYAZUDDIN, M M ANSARI \\ From the Division of Cardiothoracic Surgery, Department of General Surgery, and Department of Radiology, \\ J N Medical College, Aligarh, India
}

\begin{abstract}
A tension pneumomediastinum production features of cardiac tamponade developed in a 6 year old girl as a result of trauma. She improved dramatically when the air was released by cervical mediastinotomy.
\end{abstract}

Pneumomediastinum was first recognised by Louise Bourgeois in 1617, and was described in detail by Laennec in 1819 (cited by Munsell'). If mediastinal air is under pressure it may result in insufficient venous return to the heart, causing tachycardia, hypotension, distended neck veins, and dyspnoea-a picture similar to that of cardiac tamponade, which is very seldom seen in surgical practice." This was initially termed extrapericardial cardiac tamponade by Jehn and Nissen in 1927, ${ }^{3}$ when the physiology of cardiac tamponade was not well appreciated. In view of the paucity of such reports we describe a case of tension pneumomediastinum presenting with features similar to those of cardiac tamponade in a young girl after blunt chest trauma.

\section{Case report}

A 6 year old girl was brought to the Casualty Section of the JN Medical College Hospital with a four hour history of swelling all over her body, dyspnoea and drowsiness developing immediately after being hit on the chest by the handle of the hand pump she was running. There was no external trauma except for slight bruises over the front aspect of the chest.

On examination she had massive subcutaneous surgical emphysema all over her, most noticeable over the face, neck, and anterior aspect of the chest, and she was unable to open her eyes. She was drowsy, but there was no focal neurological deficit. She had a respiratory rate of $66 / \mathrm{min}$, a pulse rate of $140 / \mathrm{min}$, and blood pressure of $60 / 40 \mathrm{~mm} \mathrm{Hg}$. There was mild cyanosis. Neck veins were not discernible. The precordium was hyperresonant. Chest radiography (figure) showed the classical signs of tension pneumomediastinum with subcutaneous surgical emphysema.

As there were signs of cardiorespiratory embarrassment, bedside cervical mediastinotomy and two release incisions over the chest in the infraclavicular region were performed under local anaesthesia. Air streamed out under pressure. The patient showed a dramatic clinical response. Oeso-

Address for reprint requests: Dr Mohd Hanif Beg, C-4 Duplex Quarters, Sir Syed Nagar, Aligarh-202001, India. phagoscopy and bronchoscopy at this stage showed nothing abnormal. The patient continued to improve and was discharged on the seventh day with resolution of about $90 \%$ of the subcutaneous and mediastinal emphysema.

\section{Discussion}

Pneumomediastinum is an uncommon disease that often presents with subtle clinical and radiographic findings. It may result from several traumatic and pathological conditions. Air may enter from injuries of the tracheobronchial tree, neck, oesophagus, and abdomen ${ }^{4}$; and it may also enter as a result of tracheostomy $y^{5}$ or dental extraction using a high

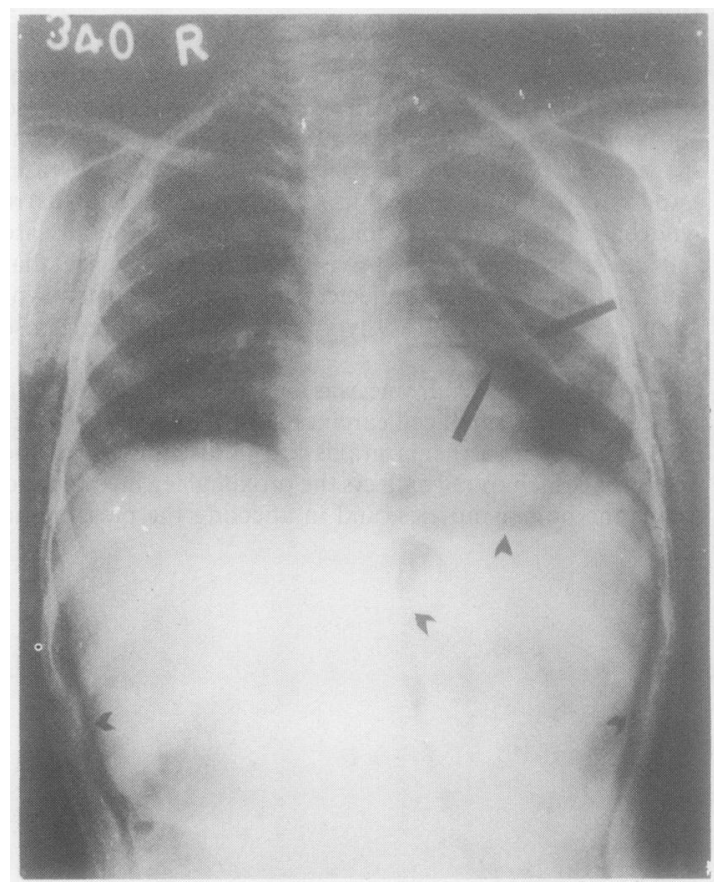

Chest radiograph showing mediastinal and subcutaneous emphysema after blunt trauma of the chest. Note the separation of the left parietal pleura from the left border of the heart by gas, giving an impression of a double line on the left contour of the heart (upper arrowheads). Note the air separating the parietal pericardium from the diaphragm (middle arrowheads), and a strip of gas that is evident in the retroperitonium (lowest arrowheads). 
speed drill. ${ }^{\circ}$ Isolated mediastinal emphysema after chest trauma is rare. Yellin et $a l^{7}$ found only five cases of isolated traumatic emphysema compared with 16 cases of the spontaneous variety over 16 years.

Increased intrapulmonary pressure from chest trauma may lead to alveolar rupture with subsequent dissection of air along the vascular structures of the lung into the hilum and from there to the tissue planes of the mediastinum. Substernal pain and crepitus in the suprasternal notch and cervical region are cardinal signs and symptoms of mediastinal emphysema. If the air in the mediastinum is under tension, it may not only spread to the face, chest, abdomen. and extremities, but also compress the great veins, thus reducing venous return to the heart. This in turn may produce clinical manifestations similar to those of cardiac tamponade ${ }^{89}$ as in our patient. The diagnosis is established by chest radiography.

The treatment of pneumomediastinum is directed towards the underlying cause, such as oesophageal or bronchial rupture. Small amounts of air in the mediastinum, in the absence of a serious underlying cause, require observation only. When a picture of tension pneumomediastinum with life threatening venous congestion develops, however, the importance of emergency cervical mediastinotomy cannot be overemphasised. The operation is simple and is completed in a few minutes under local anaesthesia. Its timely use may prove to be life saving, as in the present case.

\section{References}

1 Munsell WP. Pneumomediastinum: a report of 28 cases and review of the literature. JAMA 1967;202:689-93.

2 Glinz W. Traumatic emphysema, in chest trauma. Berlin: Springer-Verlag, 1981:149-54.

3 Jehn W, Nissen R. Pathologie und Klini des Mediastinalemphysema. Deutsch Z Chir 1927;206:221-45.

4 Sabiston DC Jr, Oldham HN Jr. The mediastinum. In: Sabiston DC, Spencer FC, eds, Gibhon's Surgery of the chest. Vol I. 4th ed. Philadelphia: WB Saunders, 1983:407-35.

5 Boyed AD, Bernhard WN, Spencer FC. Tracheal intubation and assisted ventilation. In: Sabiston DC. Spencer FC. eds. Gibhon 's Surgery of the chest. Vol I. 4th ed. Philadelphia: WB Saunders, 1983:182-96.

6 Ikard RW. Pneumomediastinum after dental extraction. South Med J 1984;77:801-2.

7 Yellin A, Gapany-Gapanavivius M. Leiberman Y. Spontaneous pneumomediastinum: is it a rare cause of chest pain? Thorax 1983;38:383-5.

8 Dripps RD. Introduction to anaesthesia. 5th ed. Philadelphia: WB Saunders, 1977:432-44.

9 Webb WR. Johnston JH. Geisler JW. Pneumomediastinum: physiologic observations. J Thorac Cardiovasc Surg 1958: 35:309-15. 